\title{
Green Approach for Fabrication and Applications of Zinc Oxide Nanoparticles
}

\author{
Brajesh Kumar, Kumari Smita, Luis Cumbal, and Alexis Debut \\ Centro de Nanociencia y Nanotecnologia, Universidad de las Fuerzas Armadas-ESPE, Avenida Gral. Rumiñahui s/n, \\ P.O. Box 171-5-231B, Sangolqui, Ecuador
}

Correspondence should be addressed to Brajesh Kumar; krmbraj@gmail.com and Luis Cumbal; lhcumbal@espe.edu.ec

Received 23 May 2014; Revised 28 August 2014; Accepted 11 September 2014; Published 14 October 2014

Academic Editor: Claudio Pettinari

Copyright (C) 2014 Brajesh Kumar et al. This is an open access article distributed under the Creative Commons Attribution License, which permits unrestricted use, distribution, and reproduction in any medium, provided the original work is properly cited.

Zinc oxide nanoparticles ( $\mathrm{ZnO}-\mathrm{NPs}$ ) are known to be one of the multifunctional inorganic compounds which are widely used in everyday applications. This study aims to fabricate $\mathrm{ZnO}$-NPs using grapefruit (Citrus paradisi) peel extract with particle size ranging from 12 to $72 \mathrm{~nm}$. Structural, morphological, and optical properties of the synthesized nanoparticles have been characterized by using UV-Vis spectrophotometer, TEM, DLS, and FTIR analysis. They show the significant photocatalytic degradation efficiency $(>56 \%, 10 \mathrm{mg} / \mathrm{L}, 6 \mathrm{~h})$ against methylene blue and antioxidant efficacy ( $\geq 80 \%$ for $1.2 \mathrm{mM})$ against 1,1-diphenyl-2-picrylhydrazyl. From the results obtained it is suggested that green $\mathrm{ZnO}-\mathrm{NPs}$ could be used effectively in environmental safety applications and also can address future medical concerns.

\section{Introduction}

In recent years, zinc oxide $(\mathrm{ZnO})$, an important semiconductor with tremendous scientific and technological interest, having a direct wide band gap $(3.37 \mathrm{eV}, 387 \mathrm{~nm}$, deep violet/borderline ultraviolet (UV)) and a large exciton-binding energy $(60 \mathrm{meV})[1]$, is a highly preferred multitasking metal oxide having a vast list of attractive properties. Due to its unique optical and electrical properties $[2,3]$, it is regarded as a potential material in optoelectronic applications operating in the visible and near ultraviolet spectral regions. Nanotechnology represents a new promising platform with a broad range of novel uses and permits the controlled synthesis of materials where at least one dimension of the structure is less than $100 \mathrm{~nm}$. Zinc oxide nanoparticles (ZnO-NPs) with the features of large volume to area ratio and high UV absorption have been widely used in many industrial areas such as solar cells [4], UV light-emitting devices [5], gas sensors $[6,7]$, photocatalysts [8], and pharmaceutical and cosmetic industries [9]. Therefore, the synthesis of $\mathrm{ZnO}-\mathrm{NPs}$ is of great interest to the researcher.

Several physical and chemical procedures have been used for the synthesis of large quantities of metal nanoparticles in a relatively short period of time. Approaches such as simple solution-based methods, chemical precipitation [10], solgel [11], solvothermal/hydrothermal [12, 13], sonochemical $[14,15]$, electrochemical, and photochemical reduction techniques are most widely used [16]. Chemical methods lead to the presence of some toxic chemicals adsorbed on the surface that may have adverse effects in medical application [17]. Some problems that are often experienced in synthesizing metal nanoparticles are stability and aggregation, control of crystal growth, morphologies, sizes, and distribution, which are important issues and continue to be solved. Thus, there is a need for "green chemistry" that offers numerous benefits of ecofriendliness and compatibility for pharmaceutical and other biomedical applications, where toxic chemicals are not used for the synthesis protocol. The use of agricultural wastes [18] or plants and their parts $[19,20]$ has emerged as an alternative to chemical synthetic procedures because it does not require elaborate processes such as intracellular synthesis and multiple purification steps or the maintenance of microbial cell cultures [21]. However biosynthesis of zinc oxide nanoparticles (ZnO-NPs) by Aloe vera [22], Bacillus cereus [23], Fusarium spp. [24], and Medicago sativa [25], as biological materials, is fully explored.

In the present study, spherical shape ZnO-NPs were synthesized and stabilized using C. paradisi outer peel 


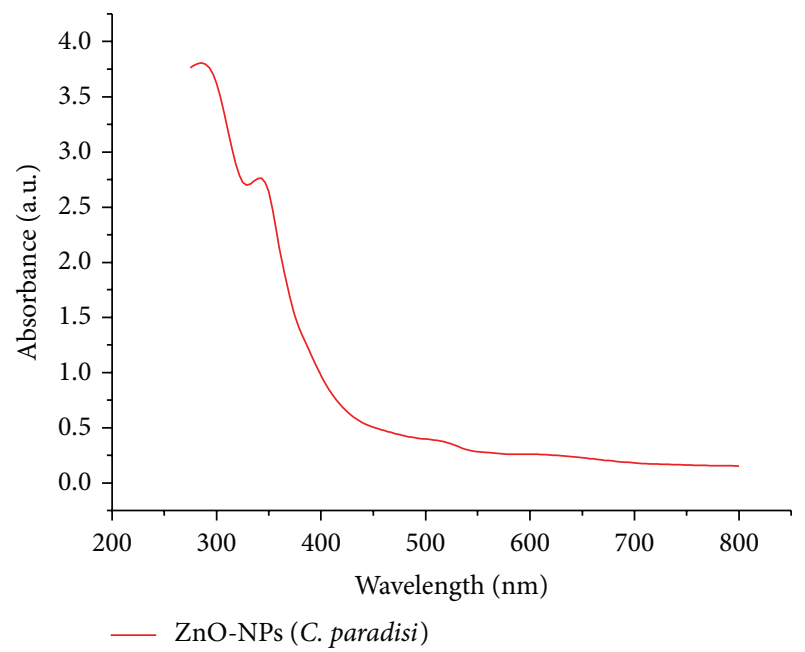

FIGURE 1: UV-Vis spectra of synthesized ZnO-NPs using C. paradisi peel extract.

extract by the bioreduction method; these nanoparticles were further investigated as (a) catalyst for the degradation of methylene blue (MB) in the presence of direct sunlight and (b) antioxidant activity using 1,1-diphenyl-2-picrylhydrazyl $\left(\mathrm{DPPH}^{\bullet}\right)$. Grapefruits (Citrus paradisi L.) are unique with sensory quality of sweet and tart taste, having red pigment in the juice vesicles and relatively high levels of bioactive compounds. The major bioactive compounds present in grapefruits include flavonoids, limonoids, carotenoids, furocoumarins, and organic acids [26, 27]. MB is one of the wellknown basic/cationic dyes and has been widely used for dying materials for wood, silk, and cotton [28]. The removal of MB from water is very important due to its toxicity.

\section{Experimental}

2.1. Materials. All chemicals used were of analytical grade and used without any purification. $\mathrm{ZnSO}_{4} \cdot 7 \mathrm{H}_{2} \mathrm{O}(>99.0 \%)$ and methylene blue $(99.5 \%)$ were purchased from the Spectrum (USA). DPPH (>99.5\%) was purchased from Sigma Aldrich, USA. Milli-Q water was used in all experiments. C. paradisi fruit was purchased from the Sangolqui local market, near Universidad de las Fuerzas Armadas-ESPE, Ecuador. The aqueous extract of C. paradisi was prepared using thoroughly washed $10 \mathrm{~g}$ of yellowish-green outer peel, boiled with $40 \mathrm{~mL}$ of double distilled water at $80^{\circ} \mathrm{C}$ for $30 \mathrm{~min}$. The extract was filtered through muslin cloth and stored in refrigerator at $4^{\circ} \mathrm{C}$ for further experiments.

2.2. Synthesis of Zinc Oxide Nanoparticles. Nanoparticles of $\mathrm{ZnO}$ were prepared using the $3 \mathrm{mM} \mathrm{ZnSO}_{4} \cdot 7 \mathrm{H}_{2} \mathrm{O}$ (aq) solution. In a typical preparation, $3 \mathrm{~mL}$ of the aqueous peel extract of C. paradisi was added to $10 \mathrm{~mL}$ of $3 \mathrm{mM} \mathrm{ZnSO} \cdot 7 \mathrm{H}_{2} \mathrm{O}$ and $\mathrm{pH}$ was adjusted to 8 , using $0.1-1 \mathrm{~mL} C$. paradisi peel extract. The mixture was stirred for 3 hours at $75-80^{\circ} \mathrm{C}$ and kept for observation up to change in the coloration. Change of color from yellowish green to light yellow was proof for the formation of $\mathrm{ZnO}-\mathrm{NPs}$. The resulting $\mathrm{ZnO}-\mathrm{NPs}$ were separated out by centrifugation at $6000 \mathrm{rpm}$ for $15 \times 2 \mathrm{mins}$, washed with deionized water (three times), and dried in a hot air oven at $150^{\circ} \mathrm{C}$ for 1 hour. Finally, the dried $\mathrm{ZnO}$ NPs (3.25 mg) were resuspended in $13 \mathrm{~mL}$ deionized water for further characterization.

2.3. Characterization. UV-Vis spectra were measured using a spectrophotometer (Thermo Spectronic, GENESYS 8, England, Quartz Cell, path length $10 \mathrm{~mm}$, and graph plotted on the Origin 6.1 program). The particle size distributions of nanoparticles were determined using the HORIBA, Dynamic Light Scattering (DLS) Version LB-550 program. Size and selective area electron diffraction (SAED) pattern of nanoparticles are studied on transmission electron microscopy (TEM) (FEI, TECNAI, G2 Spirit Twin, Holland). Fourier transform infrared (FTIR-ATR) spectra were recorded on a Perkin Elmer (Spectrum Two) spectrophotometer to hypothesized functional groups involved in the synthesis of $\mathrm{ZnO}-\mathrm{Nps}$.

2.4. Photocatalytic Degradation Study. Nanosized ZnO particle is a good photocatalyst to degrade organic contaminants, such as $\mathrm{MB}$. The photocatalytic degradation of $\mathrm{MB}$ using $\mathrm{ZnO}-\mathrm{NPs}$ is investigated with the following process: four separate sets of experiments were performed to study the decomposition of $\mathrm{MB}$ at $\mathrm{pH} 7$ in direct sunlight. In set $1,5 \mathrm{~mL}$ MB $(10 \mathrm{mg} / \mathrm{L})$ was taken in a vial and kept in sunlight. In sets $2-4$, the synthesized $\mathrm{ZnO}-\mathrm{NPs}(250 \mu \mathrm{g} / \mathrm{mL})$ were used; $5 \mathrm{~mL} \mathrm{MB}(10 \mathrm{mg} / \mathrm{L})$ and 500, 300, and $100 \mu \mathrm{L} \mathrm{ZnO}-\mathrm{NPs}$ were mixed and kept in sunlight. All four sets of reactions were observed after 1, 3, and 6 hrs. Finally, the rate of $\mathrm{MB}$ dye decomposition was monitored by taking $4 \mathrm{~mL}$ samples from each set and recording the UV-Vis spectra in the wavelength, $\lambda_{\max } 664 \mathrm{~nm}$, before and after degradation. Photocatalytic degradation percentage of $\mathrm{MB}$ was calculated using

$$
\eta=\left[1-\frac{A_{t}}{A_{0}}\right] \times 100 \%,
$$

where $\eta$ is the rate of decomposition of $\mathrm{MB}$ in terms of percentage, $A_{0}$ is the initial absorbance of $\mathrm{MB}$ solution, and $A_{t}$ is the absorbance of the dyes at time $t$.

2.5. Evaluation of Antioxidant Activity. The scavenging activity of the $\mathrm{ZnO}-\mathrm{NPs}$ was measured by using $\mathrm{DPPH}^{\bullet}$ as a free radical model and a method adapted from Kumar et al. (2014) [29] with slight modification. An aliquot (1000$200 \mu \mathrm{L})$ of ZnO-NPs $(250 \mu \mathrm{g} / \mathrm{mL})$ or control and (1000-1800 $\mu \mathrm{L})$ of $\mathrm{H}_{2} \mathrm{O}$ was mixed with $2.0 \mathrm{~mL}$ of $20 \mu \mathrm{M}\left(\mathrm{DPPH}^{\bullet}\right)$ in absolute methanol. The mixture was shaken vigorously and allowed to stand at room temperature for $30 \mathrm{~min}$ in the dark. Absorbance of the mixture was measured spectrophotometrically at $517 \mathrm{~nm}$, and the free radical scavenging activity was calculated using

$$
\begin{aligned}
& \text { Scavenging effect }(\%) \\
& \qquad=\left[1-\left\{\frac{\text { absorbance of sample }}{\text { absorbance of control }}\right\}\right] \times 100 .
\end{aligned}
$$






(a)

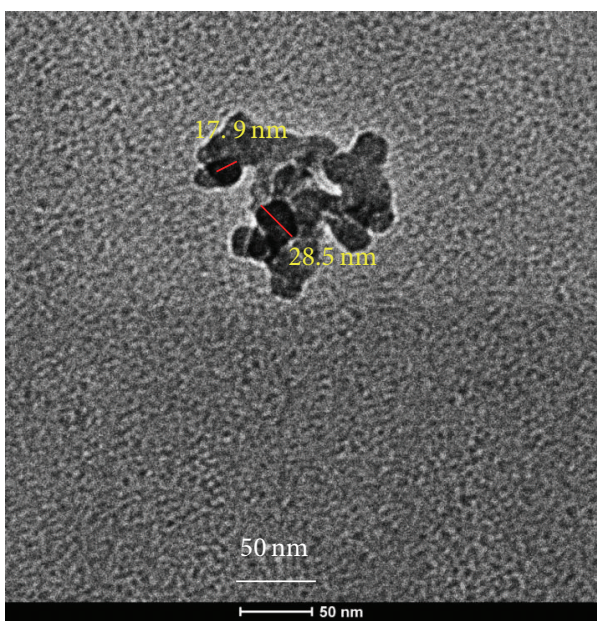

(c)



(b)

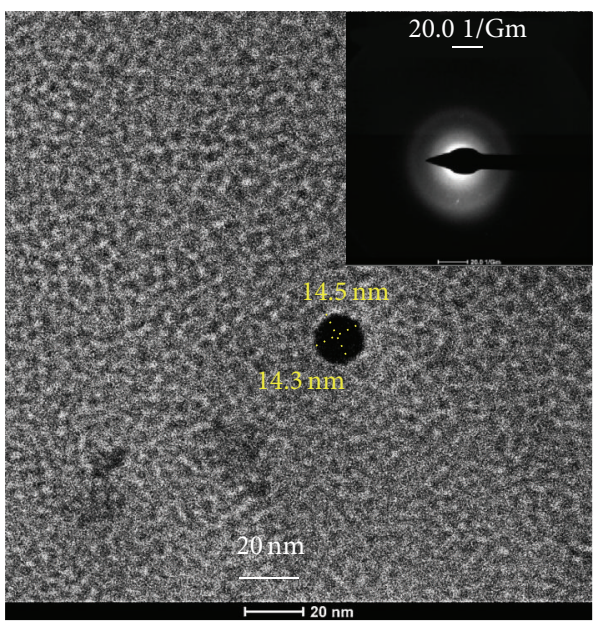

(d)

Figure 2: TEM and SAED micrograph of $\mathrm{ZnO}$ nanostructures (a-d).



Figure 3: DLS pattern of synthesized ZnO-NPs.

The scavenging percentages of all samples were plotted. The final result was expressed as $\%$ of $\mathrm{DPPH}^{*}$ free radical scavenging activity $(\mathrm{mM})$.

\section{Results and discussion}

3.1. UV-Vis Study. UV-Vis spectral analysis was used to confirm the formation of $\mathrm{ZnO}-\mathrm{NPs}$ in the solutions. UVvisible absorption spectra of the $\mathrm{ZnO}$-NPs synthesized from the mixture with aqueous peel extract of $C$. paradisi is presented in Figure 1. It is generally recognized that UVVis spectra could be used to examine the size and shape controlled nanoparticles in aqueous suspension [30, 31]. ZnO-NPs exhibit strong UV absorption spectra with the absorption peak ranging from 360 to $375 \mathrm{~nm}$ due to their excitonic transition [32].

3.2. TEM-SAED Study. The TEM monographs in Figures 2(a)-2(d) clearly show the distribution of spherical $\mathrm{ZnO}$ nanoparticles prepared by $C$. paradisi extract. The $\mathrm{ZnO}$ NPs were homogeneous and agglomerated with a particle size ranging from 12 to $72 \mathrm{~nm}$ with some deviations. The diffraction pattern in SAED images shows the crystalline nature of nanoparticles.

3.3. DLS Study. The DLS size distribution image of ZnO-NPs is shown in Figure 3. From the results, the calculated mean particle size distribution of $\mathrm{ZnO}-\mathrm{NPs}$ is $76.5 \mathrm{~nm}$ and the S.D. is $34.6 \mathrm{~nm}$ suggesting promising catalytic activity for some specific applications. 


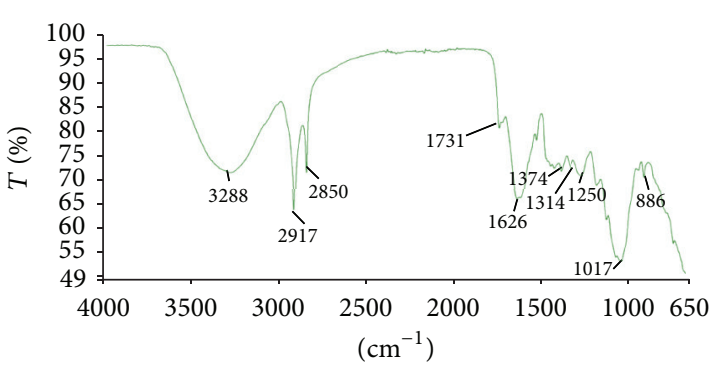

(a)

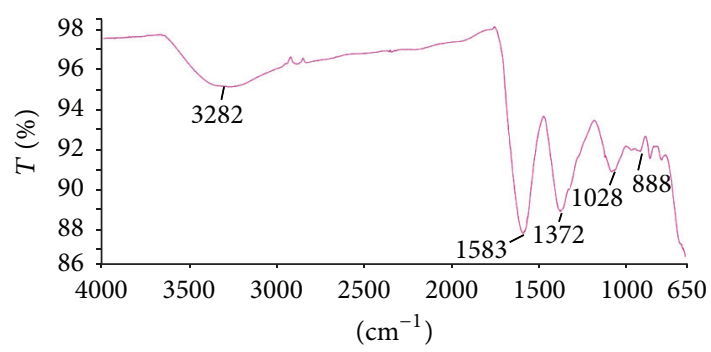

(b)

FIgURE 4: FTIR spectrum of (a) C. paradisi peel extract and (b) synthesized ZnO-NPs.

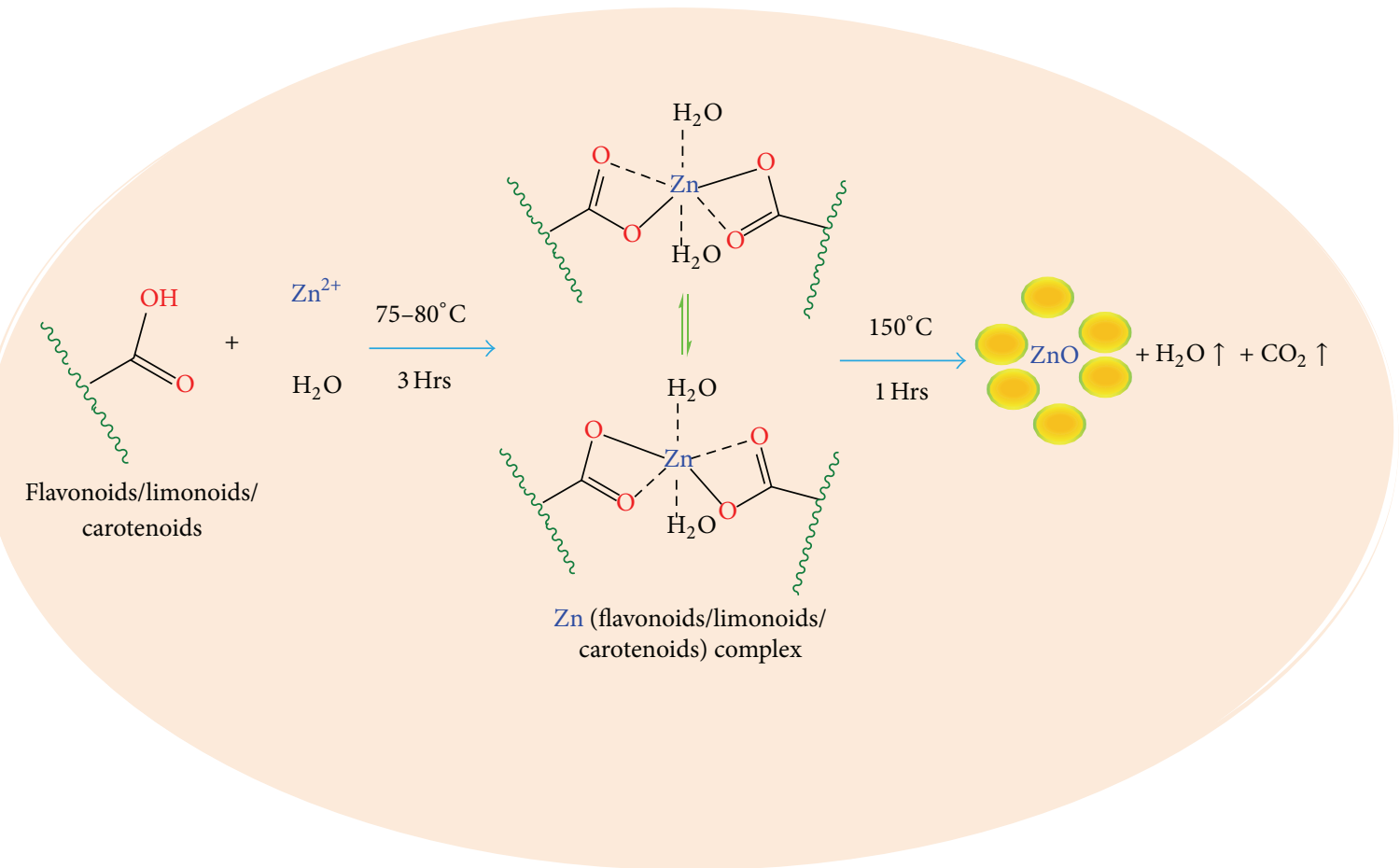

Extract coated $\mathrm{ZnO}-\mathrm{NPs}$

FIGURE 5: A tentative mechanism for the formation of $\mathrm{ZnO}-\mathrm{NPs}$.

3.4. FTIR Study. The functional groups present on the surface of $C$. paradisi peel extract and $\mathrm{ZnO}-\mathrm{NPs}$ were investigated by FTIR analysis (Figures 4(a) and 4(b)) using ATR mode. In Figure $4(\mathrm{a})$, the broad peak observed at $3288 \mathrm{~cm}^{-1}$ indicates the existence of $-\mathrm{OH}$ group, whereas the bands centered at 1731 and $1626 \mathrm{~cm}^{-1}$ can be assigned to the $\mathrm{C}=\mathrm{O}$ group. The associated peaks at $3282 \mathrm{~cm}^{-1}$ and $1731 \mathrm{~cm}^{-1}$ confirm the presence of the free $-\mathrm{COOH}$. The band observed at $2917 \mathrm{~cm}^{-1}$ and $2850 \mathrm{~cm}^{-1}$ could be assigned to the $\mathrm{C}-\mathrm{H}$ stretching vibrations of methyl, methylene, and methoxy groups [20]. The peak observed at around $1017 \mathrm{~cm}^{-1}$ indicated $\mathrm{C}-\mathrm{O}$ stretching and the peak at $1374 \mathrm{~cm}^{-1}$ can be attributed to the aromatic $\mathrm{C}=\mathrm{C}$ bond [22]. The band at $749 \mathrm{~cm}^{-1}$ signified the presence of $\mathrm{R}-\mathrm{CH}$ group. There is a slight deviation of peaks that were observed in Figure 4(b); the bonded hydroxyl groups observed at $3282 \mathrm{~cm}^{-1}$, C-O at $1028 \mathrm{~cm}^{-1}$ and $\mathrm{C}=\mathrm{O} / \mathrm{C}=\mathrm{N}$ group shifted to $1583 \mathrm{~cm}^{-1}$. It clearly indicates the involvement of $-\mathrm{OH},-\mathrm{COOH}$, and $\mathrm{C}=\mathrm{O}$ in the $\mathrm{ZnO}$ NPs synthesis. The peaks in the region below $700 \mathrm{~cm}^{-1}$ are allotted to $\mathrm{Zn}-\mathrm{O}$ [32] and it shows $\mathrm{ZnO}$-NPs absorption band near $650 \mathrm{~cm}^{-1}$. Thus, it could be concluded that the $\mathrm{ZnO}-\mathrm{NPs}$ are synthesized and stabilized by flavonoids, limonoids, and carotenoids molecules that also prevent aggregation.

3.5. A Tentative Mechanism for the Formation of ZnO-NPs. Based on our experimental results, we propose the tentative mechanism based on other works [33] for the formation of $\mathrm{ZnO}$-NPs induced by $C$. paradisi peel extracts as shown in Figure 5. The flavonoids/limonoids/carotenoid molecules have free $\mathrm{OH} / \mathrm{COOH}$, which can react with $\mathrm{ZnSO}_{4}$ to 




- $\mathrm{MB}(10 \mathrm{mg} / \mathrm{L}, 5 \mathrm{~mL})+0.5 \mathrm{~mL} \mathrm{ZnO}-\mathrm{NPs}$ - $\mathrm{MB}(10 \mathrm{mg} / \mathrm{L}, 5 \mathrm{~mL})+0.3 \mathrm{~mL} \mathrm{ZnO}-\mathrm{NPs}$

$\triangle \mathrm{MB}(10 \mathrm{mg} / \mathrm{L}, 5 \mathrm{~mL})+0.1 \mathrm{~mL} \mathrm{ZnO}-\mathrm{NPs}$

(a)

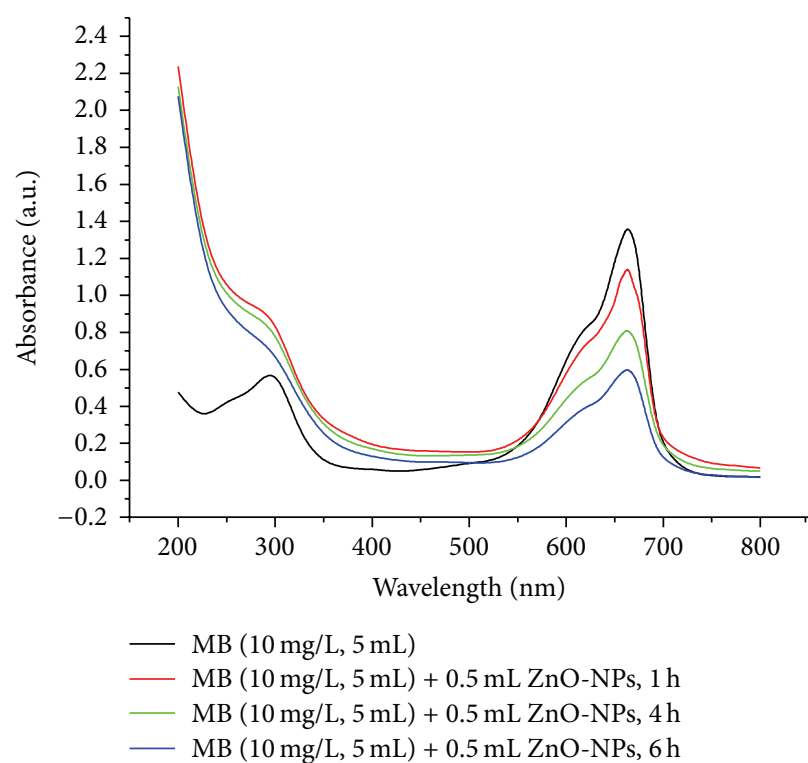

(b)

FIgURE 6: (a) Kinetic plot of $\ln \left(A_{t} / A_{0}\right) \mathrm{v} / \mathrm{s}$ time and (b) optimized photocatalytic pattern of ZnO-NPs for remediation of MB at $\mathrm{pH} 7$.

form zinc flavonoids/limonoids/carotenoid complex. After completion of the reaction, the solution was centrifuged and dried in a hot air oven. During drying, conversion of zinc flavonoids/limonoids/carotenoid complex into $\mathrm{ZnO}$ NPs takes place.

3.6. Photocatalytic Degradation of Methylene Blue. The rate of $\mathrm{MB}$ decomposition catalyzed by $\mathrm{ZnO}-\mathrm{NPs}$ is assumed to be fitted by a first-order rate law $[18,34]$ showing a linear relationship between $\ln \left(A / A_{0}\right)$ and reaction time (Figure 6(a)) and the slope gives the rate constant in each case. The optimal quantity of $\mathrm{ZnO}-\mathrm{NPs}$ for determining the photocatalytic degradation reaction is $500 \mu \mathrm{L}$. When the $\mathrm{ZnO}$ nanocatalyst quantity is $100 \mu \mathrm{L}$, the rate of photodegradation is very slow and increases with the increasing catalyst concentration. The observed rate constant for $500 \mu \mathrm{L}$ nanocatalyst is $0.002392 \mathrm{~min}^{-1}$. Methylene blue dye shows the prominent peak at $664 \mathrm{~nm}$ as shown in Figure 6(b). The peak intensity decreases gradually with the addition of $\mathrm{ZnO}-\mathrm{NPs}$ under sunlight and shows more than $56 \%$ degradation within $6 \mathrm{~h}$. A basic mechanism of photocatalytic reaction on the generation of electron-hole pair and its destination is as follows: when a photocatalyst is illuminated by the light stronger than its band gap energy, electron-hole pairs diffuse out to the surface of the photocatalyst and participate in the chemical reaction with the electron donor and acceptor. Those free electrons and holes transform the surrounding oxygen or water molecules into $\mathrm{OH}^{\bullet}$ free radicals with super strong oxidization [35].

3.7. Evaluation of Antioxidant Activity. $\mathrm{DPPH}^{\bullet}$ was first used as a preliminary radical scavenging activity test. In the $\mathrm{DPPH}^{\circ}$ method, the antioxidant reacts with the stable
$\mathrm{DPPH}^{\bullet}$ (deep violet color) and converts it into 1,1-diphenyl2-picrylhydrazine with discoloration (light yellow color). In the present study (Figure 7(a)), the percentage of free radical scavenging activity at different concentrations ranging from 0.3 to $1.5 \mathrm{mM}$ for the $\mathrm{ZnO}-\mathrm{NPs}$ for $\mathrm{DPPH}$ radical was found to increase with concentration and to peak at $\geq 80 \%$ at $1.2 \mathrm{mM}$. The antioxidant efficacy against $\mathrm{DPPH}^{\circ}$ is probably derived through the electrostatic attraction between negatively charged bioactive compounds $\left(\mathrm{COO}^{-}, \mathrm{O}^{-}\right)$of $\mathrm{C}$. paradisi and positively charged nanoparticles $\left(\mathrm{ZnO}=\mathrm{Zn}^{2+}\right.$ $+\mathrm{O}^{2-}$ ) as shown in Figure 7(b). ZnO-NPs bound to the phytochemicals and their bioactivity increases synergistically. The effect of activity depends on the site of attachment of the metals and its consequent impact on the activity of the antioxidant agent $[29,36]$. Generally, reactive oxygen species (ROS) produced by the in vitro methods mentioned above can interact with certain transition metal ions to yield a highly reactive oxidizing species (hydroxyl radicals). This antioxidant reacts further with the stable free radicals available, thereby causing their free radical scavenging activity.

\section{Conclusions}

The current study shows the green approach for fabrication of $\mathrm{ZnO}$ nanoparticles and it is responsible for significant photocatalytic and antioxidant activity. It is also believed that $C$. paradisi peel extract promotes the fabrication of the $\mathrm{ZnO}-\mathrm{NPs}$ with particle size ranging from 12 to $72 \mathrm{~nm}$. The formed $\mathrm{ZnO}-\mathrm{NPs}$ are highly stable and exhibited more than $56 \%$ degradation of $\mathrm{MB}$ in sunlight for $6.0 \mathrm{~h}$. In addition, the current study has clearly demonstrated that the $\mathrm{ZnO}-\mathrm{NPs}$ are responsible for significant antioxidant activity ( $\geq 80 \%$ for $1.2 \mathrm{mM})$. 




(a)
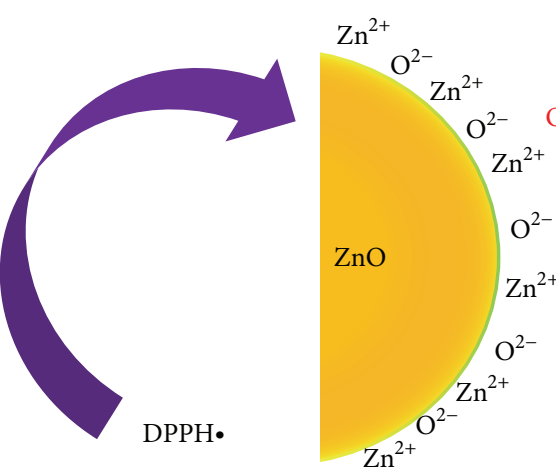<smiles>COC(=O)CSCCSC</smiles>

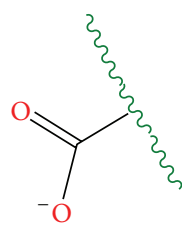

(b)

Figure 7: (a) The antioxidant efficacy of $\mathrm{ZnO}-\mathrm{NPs}$ against $\mathrm{DPPH}^{\bullet}$ and (b) most probable mechanism.

\section{Conflict of Interests}

The authors declare that there is no conflict of interests regarding the publication of this paper.

\section{Acknowledgment}

This scientific work has been funded by the Prometeo Project of the National Secretariat of Higher Education, Science, Technology and Innovation (SENESCYT), Ecuador.

\section{References}

[1] M. H. Huang, S. Mao, H. Feick et al., "Room-temperature ultraviolet nanowire nanolasers," Science, vol. 292, no. 5523, pp. 1897-1899, 2001.

[2] L. Vayssieres, K. Keis, A. Hagfeldt, and S.-E. Lindquist, “Threedimensional array of highly oriented crystalline $\mathrm{ZnO}$ microtubes," Chemistry of Materials, vol. 13, no. 12, pp. 4395-4398, 2001.

[3] R. Könenkamp, L. Dloczik, K. Ernst, and C. Olesch, "Nanostructures for solar cells with extremely thin absorbers," Physica E: Low-Dimensional Systems and Nanostructures, vol. 14, no. 1-2, pp. 219-223, 2002.

[4] W. J. E. Beek, M. M. Wienk, and R. A. J. Janssen, "Efficient hybrid solar cells from zinc oxide nanoparticles and a conjugated polymer," Advanced Materials, vol. 16, no. 12, pp. 10091013, 2004.

[5] S. J. Yang and C. R. Park, "Facile preparation of monodisperse $\mathrm{ZnO}$ quantum dots with high quality photoluminescence characteristics," Nanotechnology, vol. 19, no. 3, Article ID 035609, 2008.

[6] E. R. Waclawik, J. Chang, A. Ponzoni et al., "Functionalised zinc oxide nanowire gas sensors: enhanced $\mathrm{NO}_{2}$ gas sensor response by chemical modification of nanowire surfaces," Beilstein Journal of Nanotechnology, vol. 3, no. 1, pp. 368-377, 2012.

[7] P. Rai and Y.-T. Yu, "Citrate-assisted hydrothermal synthesis of single crystalline $\mathrm{ZnO}$ nanoparticles for gas sensor application," Sensors and Actuators B: Chemical, vol. 173, pp. 58-65, 2012.
[8] Z. Deng, M. Chen, A. Gu, and L. Wu, "A facile method to fabricate $\mathrm{ZnO}$ hollow spheres and their photocatalytic property," Journal of Physical Chemistry B, vol. 112, no. 1, pp. 16-22, 2008.

[9] J. W. Rasmussen, E. Martinez, P. Louka, and D. G. Wingett, "Zinc oxide nanoparticles for selective destruction of tumor cells and potential for drug delivery applications," Expert Opinion on Drug Delivery, vol. 7, no. 9, pp. 1063-1077, 2010.

[10] Q. Zhong and E. Matijević, "Preparation of uniform zinc oxide colloids by controlled double-jet precipitation," Journal of Materials Chemistry, vol. 6, no. 3, pp. 443-447, 1996.

[11] D. W. Bahnemann, C. Kormann, and M. R. Hoffmann, "Preparation and characterization of quantum size zinc oxide: a detailed spectroscopic study," The Journal of Physical Chemistry, vol. 91, no. 14, pp. 3789-3798, 1987.

[12] H. Zhang, D. Yang, X. Ma, Y. Ji, J. Xu, and D. Que, "Synthesis of flower-like $\mathrm{ZnO}$ nanostructures by an organic-free hydrothermal process," Nanotechnology, vol. 15, no. 5, pp. 622-626, 2004.

[13] W.-J. Li, E.-W. Shi, Y.-Q. Zheng, and Z.-W. Yin, "Hydrothermal preparation of nanometer $\mathrm{ZnO}$ powders," Journal of Materials Science Letters, vol. 20, no. 15, pp. 1381-1383, 2001.

[14] B. Kumar, K. Smita, L. Cumbal, A. Debut, and R. N. Pathak, "Sonochemical synthesis of silver nanoparticles using starch: a comparison," Bioinorganic Chemistry and Applications, vol. 2014, Article ID 784268, 8 pages, 2014.

[15] W. Chen, W. Cai, L. Zhang, and G. Wang, "Sonochemical processes and formation of gold nanoparticles within pores of mesoporous silica," Journal of Colloid and Interface Science, vol. 238, no. 2, pp. 291-295, 2001.

[16] A. Frattini, N. Pellegri, D. Nicastro, and O. De Sanctis, "Effect of amine groups in the synthesis of Ag nanoparticles using aminosilanes," Materials Chemistry and Physics, vol. 94, no. 1, pp. 148-152, 2005.

[17] D. Jain, H. K. Daima, S. Kachhwaha, and S. L. Kothari, "Synthesis of plant-mediated silver nanoparticles using papaya fruit extract and evaluation of their anti microbial activities," Digest Journal of Nanomaterials and Biostructures, vol. 4, no. 3, pp. 557-563, 2009.

[18] B. Kumar, K. Smita, L. Cumbal, and A. Debut, "Sacha inchi (Plukenetia volubilis L.) shell biomass for synthesis of silver nanocatalyst," Journal of Saudi Chemical Society, 2014. 
[19] R. G. Haverkamp and A. T. Marshall, "The mechanism of metal nanoparticle formation in plants: limits on accumulation," Journal of Nanoparticle Research, vol. 11, no. 6, pp. 1453-1463, 2009.

[20] B. Kumar, K. Smita, L. Cumbal, and A. Debut, "Biogenic synthesis of iron oxide nanoparticles for 2-arylbenzimidazole fabrication," Journal of Saudi Chemical Society, vol. 18, no. 4, pp. 364-369, 2014.

[21] N. Saifuddin, C. W. Wong, and A. A. N. Yasumira, "Rapid biosynthesis of silver nanoparticles using culture supernatant of bacteria with microwave irradiation," E-Journal of Chemistry, vol. 6, no. 1, pp. 61-70, 2009.

[22] G. Sangeetha, S. Rajeshwari, and R. Venckatesh, "Green synthesis of zinc oxide nanoparticles by aloe barbadensis miller leaf extract: structure and optical properties," Materials Research Bulletin, vol. 46, no. 12, pp. 2560-2566, 2011.

[23] M. Z. Hussein, W. H. W. N. Azmin, M. Mustafa, and A. H. Yahaya, "Bacillus cereus as a biotemplating agent for the synthesis of zinc oxide with raspberry- and plate-like structures," Journal of Inorganic Biochemistry, vol. 103, no. 8, pp. 1145-1150, 2009.

[24] P. Velmurugan, J. Shim, Y. You et al., "Removal of zinc by live, dead, and dried biomass of Fusarium spp. isolated from the abandoned-metal mine in South Korea and its perspective of producing nanocrystals," Journal of Hazardous Materials, vol. 182, no. 1-3, pp. 317-324, 2010.

[25] G. Canizal, P. S. Schabes-Retchkiman, U. Pal, H. B. Liu, and J. A. Ascencio, "Controlled synthesis of $\mathrm{Zn}^{0}$ nanoparticles by bioreduction," Materials Chemistry and Physics, vol. 97, no. 2-3, pp. 321-329, 2006.

[26] G. K. Jayaprakasha, D. V. Dandekar, S. E. Tichy, and B. S. Patil, "Simultaneous separation and identification of limonoids from citrus using liquid chromatography-collision-induced dissociation mass spectra," Journal of Separation Science, vol. 34, no. 1, pp. 2-10, 2011.

[27] R. M. Uckoo, G. K. Jayaprakasha, and B. S. Patil, "Rapid separation method of polymethoxyflavones from citrus using flash chromatography," Separation and Purification Technology, vol. 81, no. 2, pp. 151-158, 2011.

[28] M. Rafatullah, O. Sulaiman, R. Hashim, and A. Ahmad, "Adsorption of methylene blue on low-cost adsorbents: a review," Journal of Hazardous Materials, vol. 177, no. 1-3, pp. 7080, 2010.

[29] B. Kumar, K. Smita, L. Cumbal, and A. Debut, "Synthesis of silver nanoparticles using sacha inchi ( Plukenetia volubilis L.) leaf extracts," Saudi Journal of Biological Sciences, 2014.

[30] U. Pal, J. G. Serrano, P. Santiago, G. Xiong, K. B. Ucer, and R. T. Williams, "Synthesis and optical properties of $\mathrm{ZnO}$ nanostructures with different morphologies," Optical Materials, vol. 29, no. 1, pp. 65-69, 2006.

[31] U. Pal and P. Santiago, "Controlling the morphology of $\mathrm{ZnO}$ nanostructures in a low-temperature hydrothermal process," Journal of Physical Chemistry B, vol. 109, no. 32, pp. 15317-15321, 2005.

[32] G. Muñoz-Hernández, A. Escobedo-Morales, and U. Pal, "Thermolytic growth of $\mathrm{ZnO}$ nanocrystals: morphology control and optical properties," Crystal Growth and Design, vol. 9, no. 1, pp. 297-300, 2009.

[33] J. Qu, C. Luo, and J. Hou, "Synthesis of $\mathrm{ZnO}$ nanoparticles from Zn-hyperaccumulator (Sedum alfredii Hance) plants," Micro and Nano Letters, vol. 6, no. 3, pp. 174-176, 2011.
[34] B. Kumar, K. Smita, L. Cumbal, and A. Debut, "Sacha inchi (Plukenetia volubilis L.) oil for one pot synthesis of silver nanocatalyst: an ecofriendly approach," Industrial Crops and Products, vol. 58, pp. 238-243, 2014.

[35] Y. J. Jang, C. Simer, and T. Ohm, "Comparison of zinc oxide nanoparticles and its nano-crystalline particles on the photocatalytic degradation of methylene blue," Materials Research Bulletin, vol. 41, no. 1, pp. 67-77, 2006.

[36] L. Du, S. Suo, G. Wang et al., "Mechanism and cellular kinetic studies of the enhancement of antioxidant activity by using surface-functionalized gold nanoparticles," Chemistry A: European Journal, vol. 19, no. 4, pp. 1281-1287, 2013. 

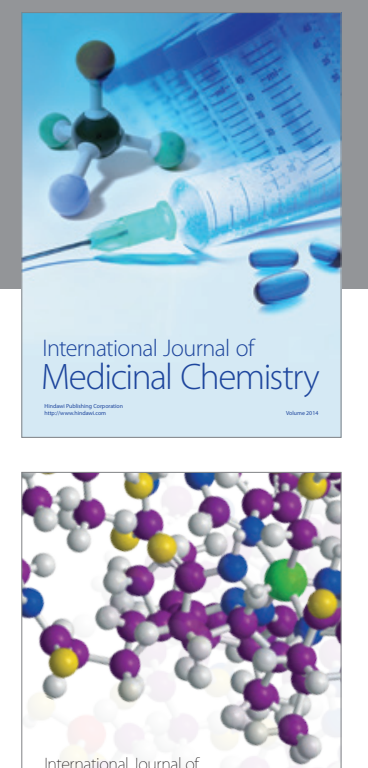

\section{Carbohydrate} Chemistry

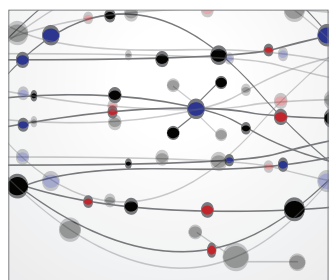

The Scientific World Journal
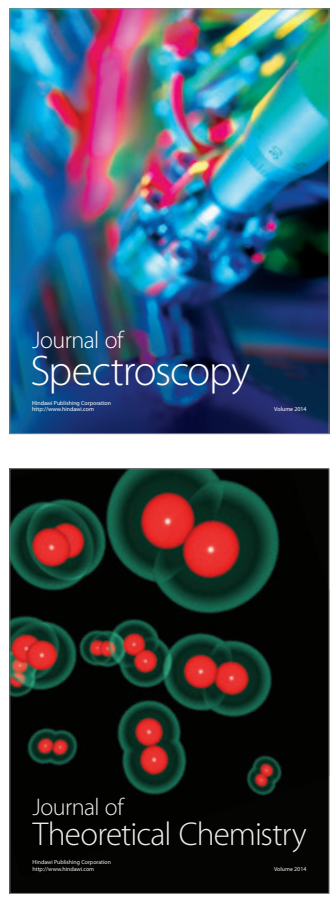
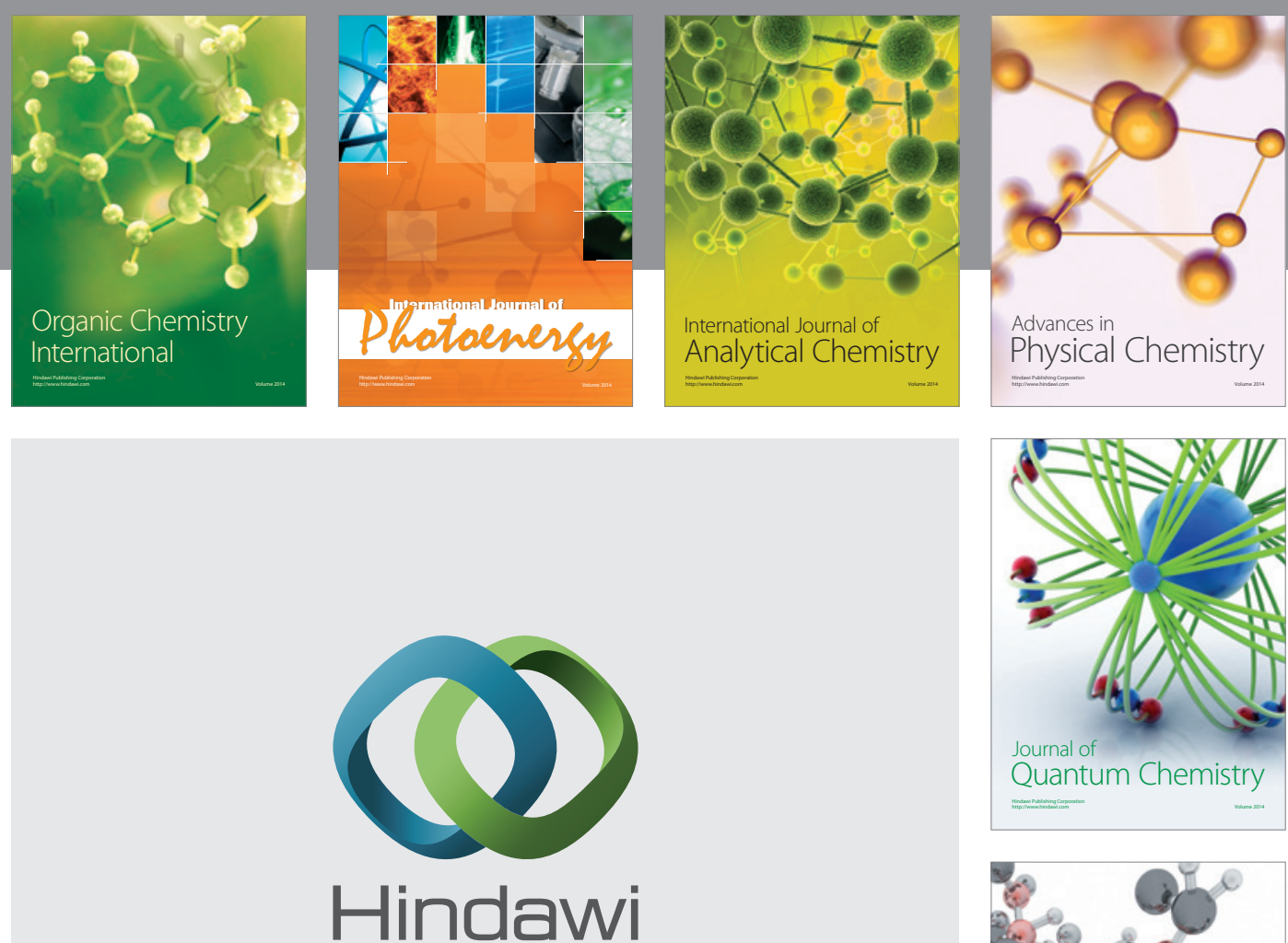

Submit your manuscripts at

http://www.hindawi.com

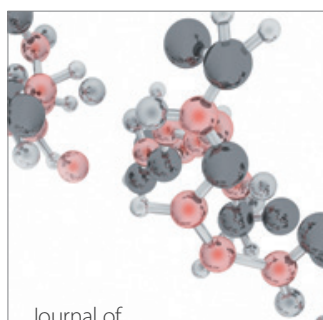

Analytical Methods

in Chemistry

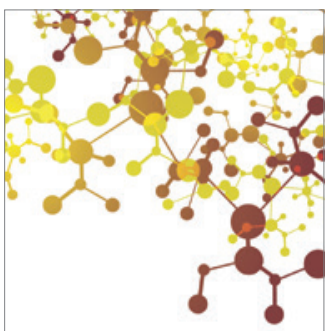

Journal of

Applied Chemistry

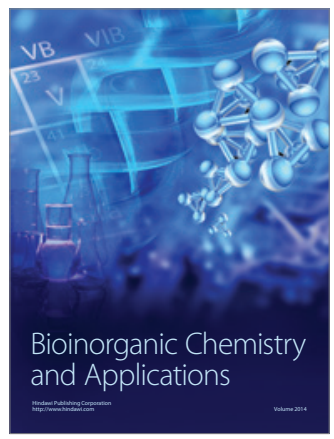

Inorganic Chemistry
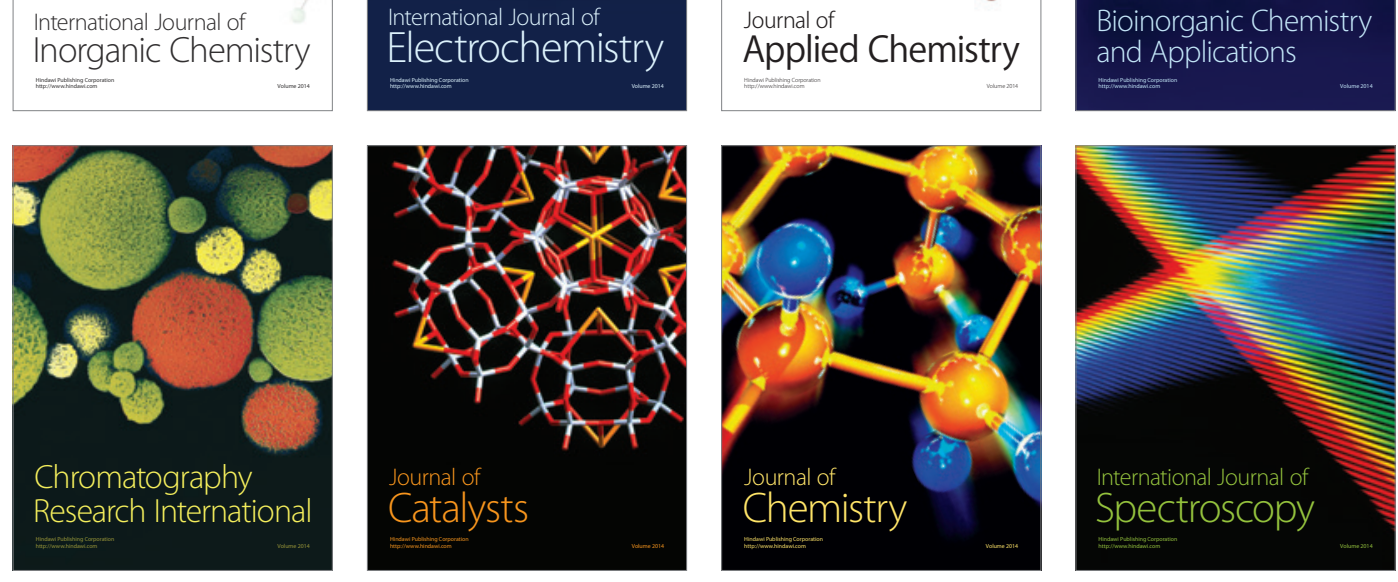